\title{
A Brief of Sources of injury and failure during stent implantation
}

\author{
Al Emran Ismail ${ }^{1}$, Abdul Fatah Mat Beyi ${ }^{2}$ \\ Faculty of Mechanical and Manufacturing Engineering, Universiti Tun Hussein Onn Malaysia, 86400, Malaysia, \\ 1emran@uthm.edu.my / al_emran@ hotmail.com, ${ }^{2}$ abdfattah43@gmail.com
}

\begin{abstract}
Blockage of plaque in the artery would harden as the calcification process take place. Angioplasty stenting or called atherosclerosis treatment was where the diseased artery will be inserted a balloon with a stent. Then, removal of the balloon will take place as the inflation of the expanded stent occurred when it reached the diseased site. However, the stent could still function well although deformation of plastic occurred. It was because the space in the artery still opens due to the scaffold. Process of the deployment of the stent would harm the plaque or the artery [1]. The mechanical process needed to be fully understood to prevent this event from happening.
\end{abstract}

Key words: blockage of plaque, stent, angioplasty stenting, artery.

\section{INTRODUCTION}

Endovascular stents extend the blood vessel wall than inflatable angioplasty and minimize the rates of restenosis after coronary angioplasty in patients [2]. Moreover, the stent struts would impose the deep vascular trauma [3-4] for experimental of animals and humans, abundant internal hyperplasia would produce more than balloon angioplasty $[2$, 5-7].

Successful treatments for establishing in-stent restenosis could be identified if all the practical elements of in-stent restenosis fully understood and rate of failure could be reduced. An optimized stent design such as stent geometry and stent materials or protocols placement such as the selection of balloon and inflation pressure could be used to know the factors involved during implantation of a stent to avoid vascular injury. This also will help in reducing the restenosis beside to limit the vascular injury.

Notwithstanding mechanical factors, for example, central deep damage from struts and in general blood vessel strain, which have significant jobs in inciting in-stent restenosis, as of late detailed that stent arrangement prompts fractional denudation of the endothelium to each configuration of stent in unique pattern, proposing inflatable related injury [1] appropriation of artery vascular damage caused amid stent implantation is a marker of the endothelial denudation. Successful treatments for establishing in-stent restenosis could be identified if all the practical elements of in-stent restenosis fully understood and rate of failure could be reduced. An optimized stent design such as stent-strut geometry and material or protocols placement such as the selection of balloon and inflation pressure could be used to know the factors involved during implantation of a stent to avoid vascular injury. This also will help in reducing the restenosis beside to limit the vascular injury.

\section{BALLOON-ARTERY INTERACTIONS}

Experimental neointimal hyperplasia produced because of underlying smooth muscle cells and injury to endothelial cells [4]. While mild neointimal thickening produced by denudation of endothelial cells alone [8]. Then medial smooth muscle cells direct injury because of more substantial neointimal hyperplasia [9]. There was something exists between the extent of intimal thickening and the depth of arterial injury called correlation in stented arteries [3]. Greater neointimal hyperplasia in humans due to larger balloon sizes and higher inflation pressure [10]. There are several mechanisms such as the stress cause by the ballon deployment may be a determinant of restenosis including effects of either time-dependent loading or fatigue stress on the artery wall [10]. An accurate predictor of later luminal loss possible if luminal stretching at the time of angioplasty acute [11, 12].

Interactions between balloon and artery vessel wall would result in surface injury especially during stent deployment. Two opposite elements of the ballooning mechanisms and arterial vessel interactions involve during stent placement including arterial displacement and balloon extrusion. Both the surfaces of ballon and arterial wall are totally soft and tender but the balloon would extrude if follow the total rigidity of artery law [1]. During and after balloon expansion, the artery would prolapse into the stent-strut interstices if total rigidity or low compliance of the balloon taken into consideration.

The superficial and deep arterial injury also could happen by plastically stressed condition imposed by stent struts and strain even after balloon withdrawal during stent deformation. Blood trapped to the closed space between balloon surface, stent strut, and the arterial luminal wall 
would cause fluid-shear stress which was identified distributeing surface stress equally over the entire struct area Interactions between balloon and artery vessel wall would result in superficial injury during stent deployment. Two opposite elements of the balloon and arterial vessel interactions involve during stent placement including arterial displacement and balloon extrusion. Both outer surface of ballon and inner arterial wall are not totally rigid but the balloon would extrude if follow the total rigidity of artery law [1].

\section{SOURCES OF INJURY}

Researchers investigated the contact of balloon-artery form the arterial wall as the stress and force transmitted [1]. FEA was chosen to construct the model of the balloon and artery and the force was determined as the boundary conditions chosen between two stent struts applied to mimic the extruding of the balloon. The stress developed during the expansion of stent within the arterial wall was modelled from the surface force. Reflecting stent design or strut distance and expansion pressure of balloon were studied. FEA result shows that maximum surface contact stress increase as the strut distance grew and the contact area was normalized as shown in Fig. 1. This is to confirm that reducing the stress in the contact areas during the stent deployment significantly affected the way of stent designs.
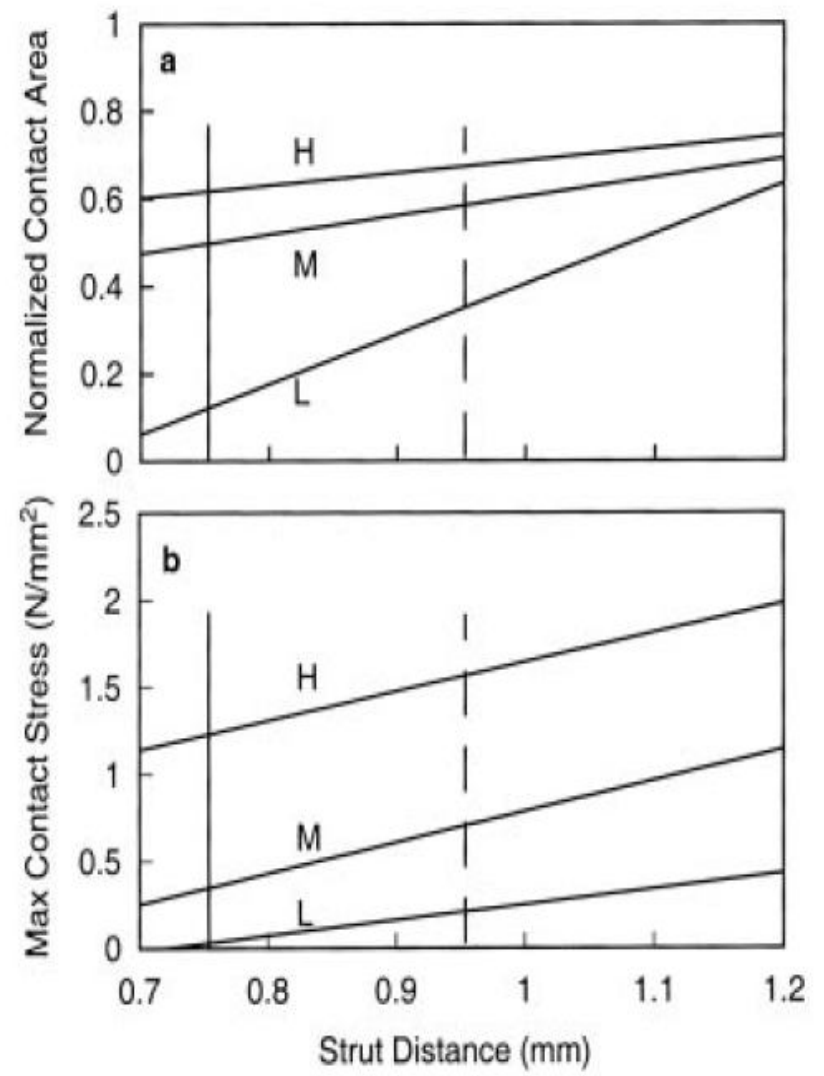

Figure 1: Relationships between normalized contact area shown inline graph analysis (a) maximum the stress (b) strut distance or balloon material compliance [1].

\section{MECHANICAL FAILURE OF STENTS}

Blood flow in atherosclerotic peripheral could be restored but the success is low relative to coronary arteries. Stent placement would be highly incompatible in the arteries as the joint flexion induces a mechanical environment. A side effect is, it is still unknown what the environment can do on the stress in the arteries. What can be concluded is the low success rate is because of the mechanical environment. Higher number of stent failure especially in the popliteal and femoral are still unknown.

The variation in success rates could be explained by understanding the differences between peripheral and coronary arteries [13]. First is the size of stents used in coronary arteries and peripheral arteries which are respectively less than $4 \mathrm{~mm}$ in diameter and up to $10 \mathrm{~mm}$ in diameter. Stents used to remove blockages in peripheral arteries were longer compared to coronary arteries. It can be as long as $80 \mathrm{~mm}$ for single peripheral stents. Next, the difference is a composition with distance from the heart and the variation in vessel wall thickness. During pulsatile blood flow, the volumetric change allowed as the arteries positioned closed to the heart is considerably elastic but different from peripheral arteries, it did not distend too much and more muscular. Lastly, the arteries differ in the shape of the waveforms but both are subject to time-dependent-loading cycles. Other components of loading are significant different as the coronary and iliac arteries are comparable in term of maximum and minimum pressures [14].

Stent geometries in the main strut after deployment and side branch balloon after subsequent dilatation showed in Fig. 2. Both the main strut and the side branch patency have been clearly in a state of the expanded stent. Stent struts of side branch allow the balloon expanded. Two stents which are main branch and the side branch plays an important role during T-stenting, a bifurcation stenting technique. All floating struts should disappear as the vessel wall make contact with the stent material. Fig. 2 shown different situation because non-contant struts still occur for both stent designs. This situation showed the existence of thrombosis formation. Balloon inflation and balloon size effect cause the opening of the stent in front of the side branch.
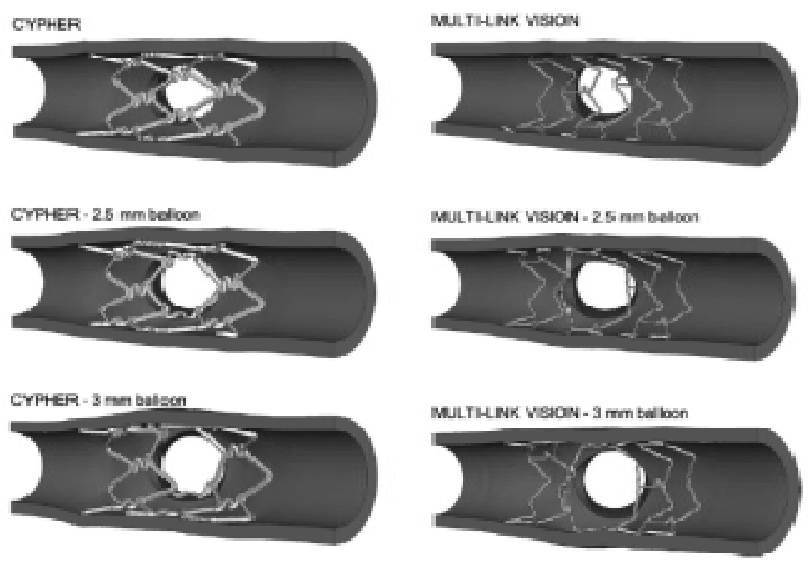

Figure 2: Stent geometrical disorder after expansion in the main branch and subsequent mechanisms. [15] 
Fig. 3 shown dilating through the side of a stent compromise form the main branch lumen. Ormiston et al. (1999) observed the same phenomenon from the five different stent designs in vitro tests [15]. Deformation observed in vitro of the Multi-Link-stent shown that distortion of the Multi-Link Vision stent corresponds well. Different designs consist of ring elements with three connection elements and each of them has two subsequent rings. Fig. 4 illustrates the deformation behaviour type. Stent design strongly affects the result as it will have a minor effect in contrast to the balloon size.
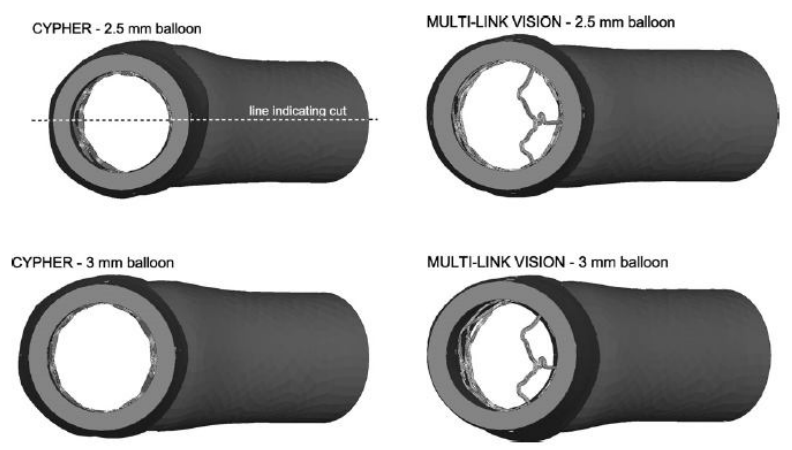

Figure 3: Main branch view from proximal side showing the impact of the side branch balloon dilatation on the main branch lumen [15].
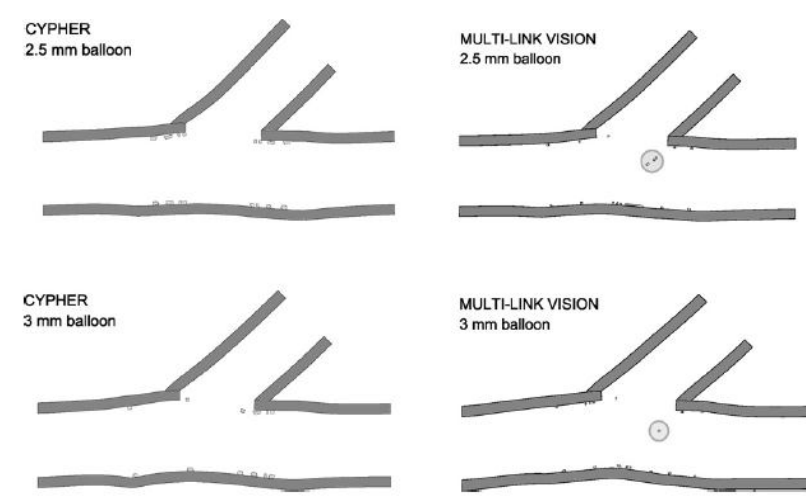

Figure 4. Side view showing the stent strut positions. Floating struts in the main branch lumen shown in the small circle [15].

Coronary artery at the right and left anterior descending are both coronary arteries that attached to the myocardium. Ding et a., (2002) reported the behaviour of these kind of arteries over two cardiac cycles $[16,17]$. For both arteries, there have been reported the existence of bending, torsion and also significant displacement. Relation of influence of vessel deformation and hemodynamics have been investigated but motion influence as arterial stress still not fully understood $[16,18,19]$. Fig. 5 showing the right coronary artery (RCA) tracking in a biplane sequence. The entire cardiac cycle was cover $\mathrm{n}$ the sequence comprises of 11 frames. The three casings of the 11-outline cardiovascular cycle are dispersed $0.2 \mathrm{~s}$ separated. The hub is appeared every projection and in $3 \mathrm{D}$ space. Note how the utilization of neighbourhood windows permits the branch point to be followed amid the cycle, even where there is overlap.

The joint movement would influence the mechanical conditions of the peripheral arteries. Even healthy patients would have complications such as flexion of the knee that cause occlusion of the popliteal artery [20]. Bending effect in the artery was the impact of the flexion of the knee. Duda et al., (2001) introduced the hinge point concept in stented arteries as the vessel movement and compression might introduce [21]. Diaz et al supported this concept that flexion of the knee can up to $100 \%$ PAD affect the location of hinge points in popliteal arteries [22]. Then, the different theory said that coronary arteries less bending compared to an inspection of angiograms during knee flexion [2, 22]. Kroger et al., (2004) and Solis et al., (2006) reported that stents in the distal femoral and popliteal arteries experienced extreme mechanical environment due to joint flexion [23, 24].
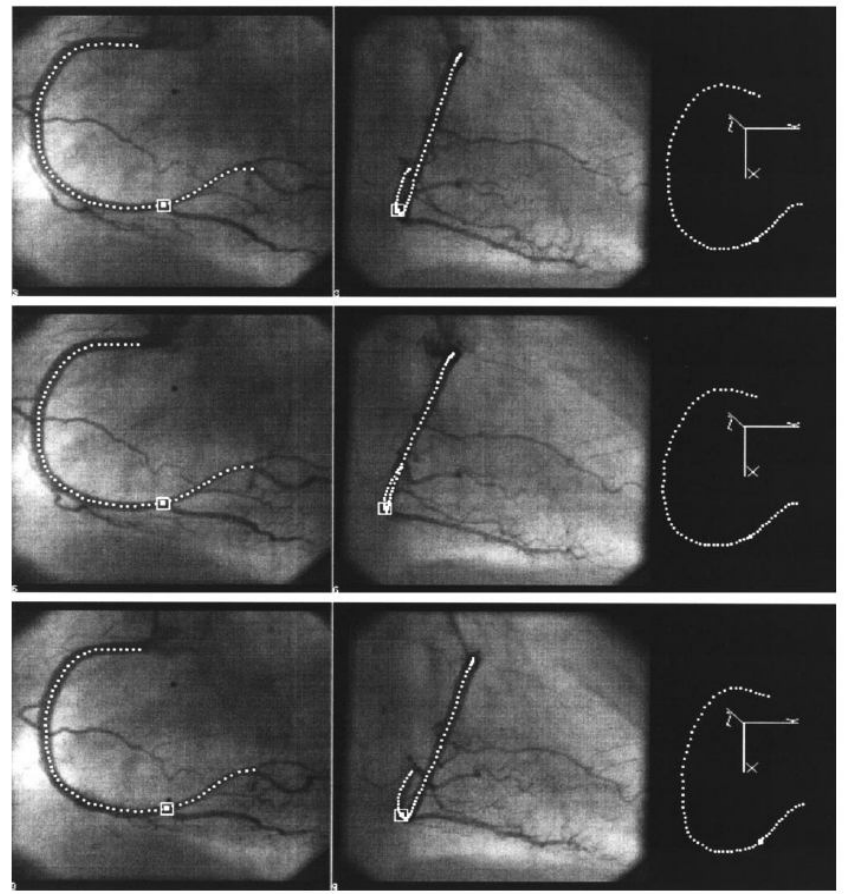

Figure 5: Illustration of stent tracking of the right coronary artery. [17]

\section{FAILURE OF STENT EXPANSION}

Based on the analysis [25], no sudden death or other complications such as lobe collapse, fistula formation and pneumothorax. 68 patients undergoing Ultraflex self-expanding metal stents insertion and well documented. Complications included hemorrhage originating and malignant tracheobronchial stenosis during the insertion in the area of the stent placement. The complications were mild hemoptysis (5 patients), stent migration (4 patients), odynophagia, respiratory failure, stent occlusion, and deployment failure (1 patient in each case).

Saad et al., (2003) reported other complications such as the occurrence of infection in $15.9 \%$, obstructive granulomas (14.6\%), and migration in $4.7 \%$ involving 82 patients [26]. 
Antibiotics could effectively treat infectious tracheobronchitis which was another common complication [26]. Lower respiratory tract infections post stenting would cause the mortality resulting and significant morbidity.

SEMS expansion failure was very rare in tracheobronchial stenting. Deployment failure also had been reported by McGrath et al., (2012) but did not describe the details [25]. Malfunction of the stent deployment system [27] has been reported by Dimofte et al., as the patient with oesophagal malignant stenosis from the case of incomplete deployment of an oesophagal expandable metallic stent.

Fig. 6 show the comparison of Ultraflex metal stent. The stent was stored in the climate-controlled environment in the operation theatre at the temperature of 23-degree centigrade and was within the expiry date. From the for the failure of stent expansion, two discussions were issued. First, the compressive effect on the stent was the reason the stent did not open because of the tight stenosis of the trachea. Next, technical defect itself cause the stent failed to expand. From the report [28], it said that no patient suffers any bad complication Saad et al., self-expandable metallic airway stents and flexible bronchoscopy: long-term outcomes analysis. Chest [2] reported other complications such as the occurrence of infection in $15.9 \%$, obstructive granulomas $(14.6 \%)$, and migration in $4.7 \%$ involving 82 patients. Antibiotics could effectively treat Infectious tracheobronchitis which was another common complication [26]. Lower respiratory tract infections post stenting would cause the mortality resulting and significant morbidity.

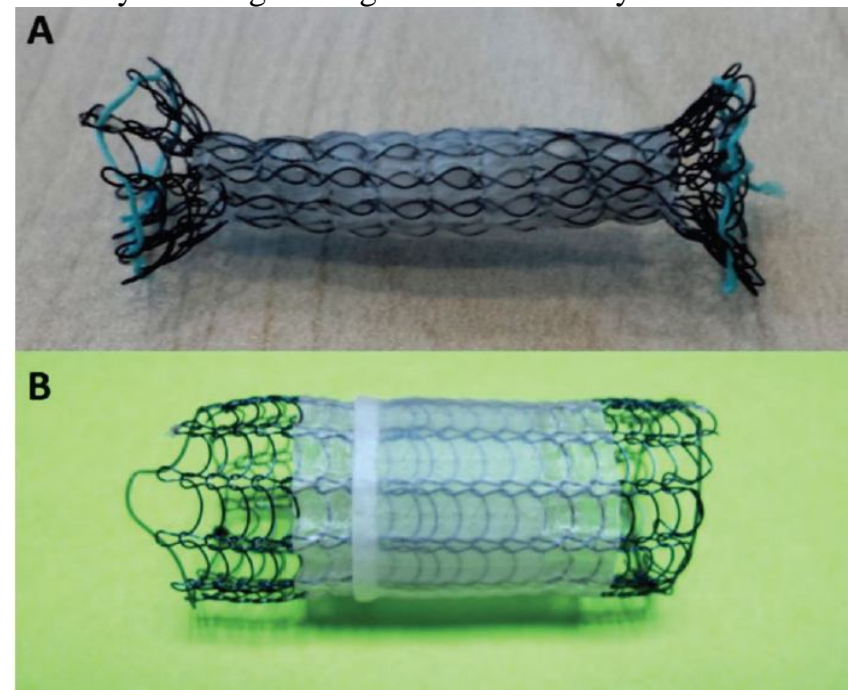

Figure 6: (A) Covered Ultra-flex metal stent failed expansion and $(B)$ covered Ultra-flex metal stent normally expanded [28]

\section{STENTING IN ANIMAL STUDIES}

Damage and injury in artery were the cause of the rate of restenosis in addition to stent deployment [29]. Restenosis was promoted by stress in the artery. That was why stent with less stress in the arterial wall safe. Two factors responsible to produce higher stresses are during stent deployment and bending of the vessel [30-33].
Failure that occurred was investigated by the researchers in arteries of rabbit [10]. The inflation pressure angioplasty failures occurred with the highest percentage which was $76 \%$ from 25 arteries investigated. $6 \%$ for Acute vessel closure. Next, 6\% for each, oversized balloon and high inflation pressure. Fig. 7 shown the series of angiograms of balloon angioplasty before and after.
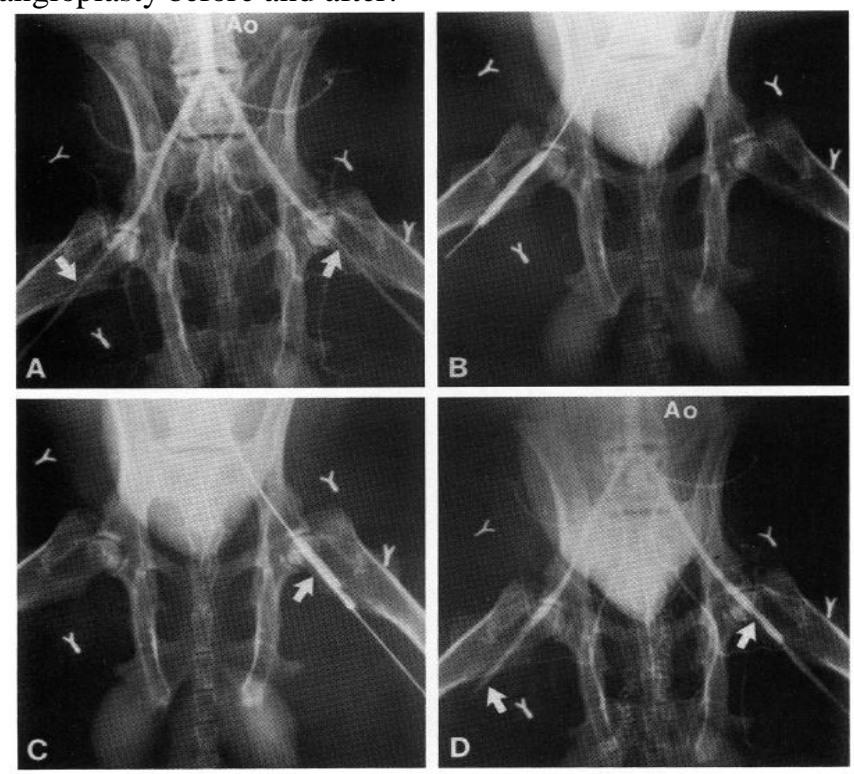

Figure 7: A progression of angiograms previously (pre) and 10 minutes after (post) two-sided femoral supply route expand angioplasty utilizing a 3.0-mm swell and a 5-or 10-atm expansion weight. (A): Pre-angioplasty angiogram: Bilateral central femoral atherosclerotic injuries are the arrowed, aorta. (B): Three-millimeter swell was expanded to 10 atm crosswise over right femoral stenosis. (C): Five breaths of air swelling over the left femoral stenosis. Note abdomen in the inflatable at the site of maximal narrowing. (D): Ten-minute postangioplasty angiogram with intense vessel conclusion at the site of high-weight angioplasty. Left femoral supply route angioplasty was effective. [10]

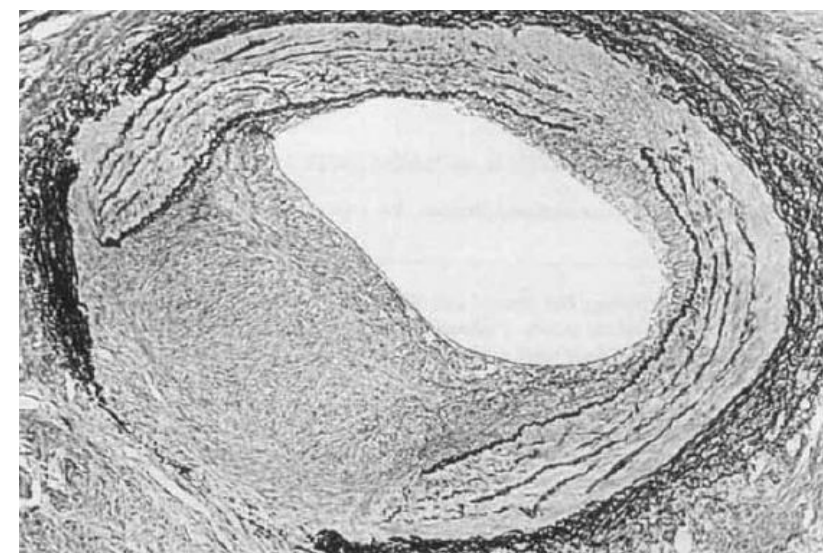

Figure 8: Balloon inflation injury to a porcine coronary artery. Lower left site is where the larger lacerations of the internal elastic lamina are associated with more neointima while larger lacerations of the lamina cause larger neointimal growth at the upper right site [29] 
Restenosis neointimal hyperplasia and acute thrombosis were the most stent problems. Earlier, the animal became a model for stent development as the problems cannot be easily developed in patients. Fig. 8 shown balloon inflation and the response of the coronary artery injury of porcine. Neointimal hyperplasia formed in pig coronary artery in response to stent placement. Hyperplasia in human restenosis same in term of histopathological appearance, density and size. Oversized balloon inflation produced the neointimal formation but not specific for stent injury [29].

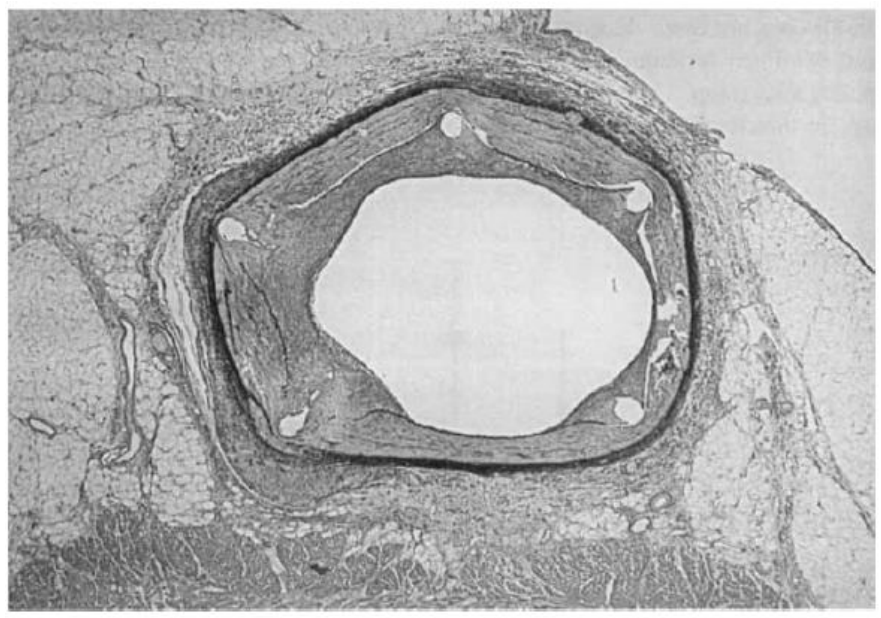

Figure 9: Artery damage caused by the oversize stent. [29]

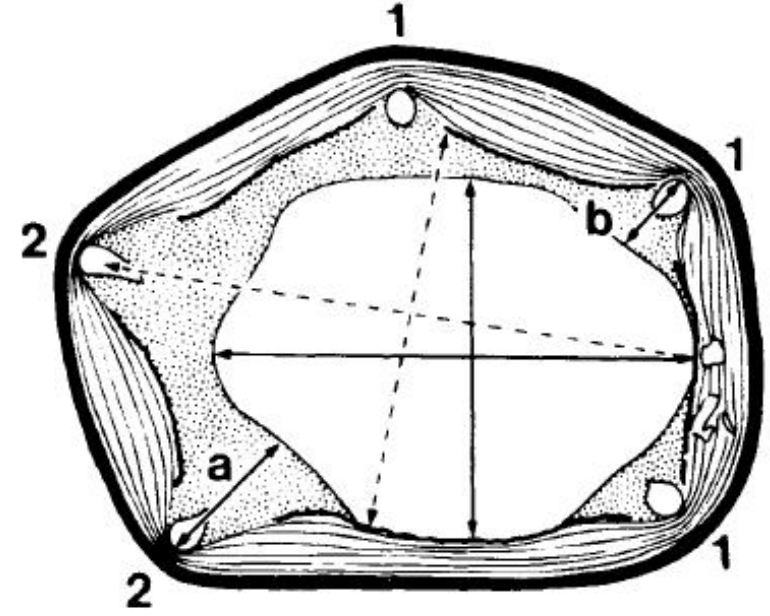

Figure 10: Schematic drawing of relating injury depth to noninternal thickness [29].

Fig. 9 and Fig. 10 show the sample of pig artery that use in the experiment. Neointimal thickness and depth of injury relationship prove the histopathological examination of stented cross-sections. Different depth of injury of stent used, more neointima causing less injury. Cross-over effect of injury sites suggested in this condition. Diffusible growth factors and thrombus connecting the two wires early were the possibilities for the injury. Different depths of injury had been created after 28 days of the injury. More injury was at two wires farthest compare to those three wires on the right.
Two coronary vessels are implanted with oversized wire-stent was tested on seven baboons using techniques same to the pigs. All the baboons survived for 3 days the stent implant. However, three died. Fig. 11 shown the thrombi appeared which was same as the pigs and (humans) presumably. The region was densely full with erythrocyte, platelets and fibrin. Two small arrows showed the stem wire surrounding with older fibrin-rich thrombus. The large arrow is shown in rich areas of typical platelet-rich and fibrin/erythrocyte.

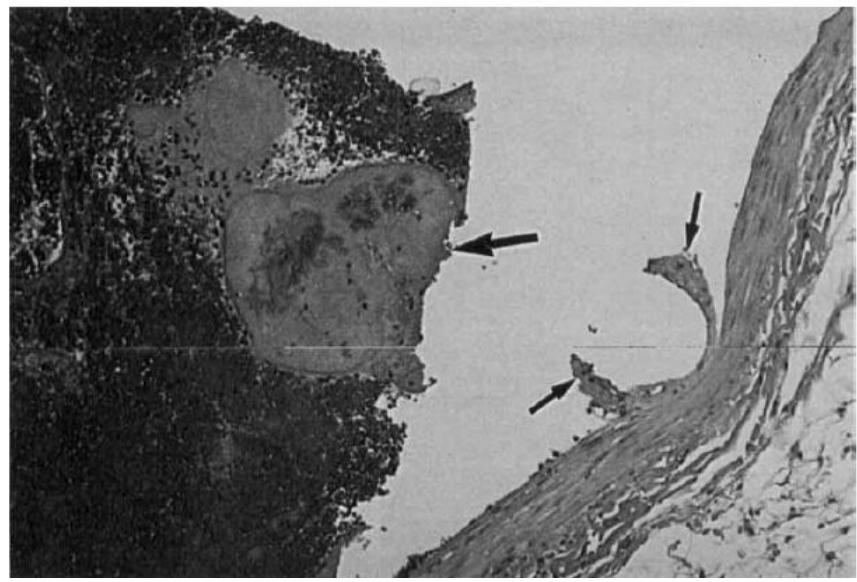

Figure 11: An oversized stent implant in a baboon coronary artery [29].

\section{CONCLUSION}

Undeniable, due to ease of deployment, palliation of malignant central airway obstruction could be solved with SEMS. However, failure of expansion in the airway after deployment can be a potentially hazardous complication. This unusual complication must always be taken into considerations to ensure safety during stent insertion Although the technology remains in its infancy, the face of interventional cardiology is changing by the coronary stent. As the stent is able to eliminate thrombosis. the future holds great promise limit neointimal hyperplasia and to seal dissections. The hope for patients undergoing percutaneous revascularization to be leaved behind by the procedure will be a great future in the medical world. Only animal models that well-understood was the key to be through these extensive studies.

\section{ACKNOWLEDGEMENT}

Authors acknowledge the financial support to Research Fund E15501, Research Management Centre, Universiti Tun Hussein Onn Malaysia. 


\section{REFERENCES}

1. C. Rogers, D. Y. Tseng, J. C. Squire, and E. R. Edelman. Design as Contributors to Vascular Injury, October, pp. 378-383, 1999.

https://doi.org/10.1161/01.RES.84.4.378

2. F. Negro, A. Mondardini, and F. Palmas. A Randomized Comparison of Coronary Stent Placement and Balloon Angioplasty in the Treatment of Coronary Artery Disease. N. Engl. J. Med., vol. 331, no. 2, pp. 134-135, 1994.

3. R. S. Schwartz et al. Restenosis and the proportional neointimal response to coronary artery injury: Results in a porcine model, J. Am. Coll. Cardiol., vol. 19, no. 2, pp. 267-274, 1992.

4. R. S. Schwartz, D. R. Holmes, E. J. Topol, and F. Acc. The Restenosis Paradigm Revisited: An Alternative Proposal for Cellular Mechanisms, vol. 20, no. 5, pp. 1284-1293, 1992.

5. C. Rogers, M. J. Karnovsky, and E. R. Edelman, Inhibition of Experimental Neointimal Hyperplasia and Thrombosis Depends on the Type of Vascular Injury and the Site of Drug Administration, pp. 1215-1221.

6. K. R. Karsch, Prolonged proliferative response of smooth muscle cells after experimental intravascular stenting, pp. 785-793, 1995.

7. W. Dupont, D. PAGE, F. Parl, C. Vnencak-Jones, W. J. Plummer, and M. Rados, Caveats about Elective Coronary Stenting, no. 15, pp. 800-802, 1994.

8. R. Hoffmann, P. Haager, G. S. Mintz, G. Kerckhoff, R. Schwarz, A. Franke, J. vom Dahl, and P. Hanrath, The impact of high-pressure vs low-pressure stent implantation on intimal hyperplasia and follow-up lumen dimensions Results of a randomized trial, no. 2001, pp. 2015-2024, 2015.

9. Donald Y. M. Leung, Seymour Glagov and Martin B. Mathewsvol. Cyclic Stretching Stimulates Synthesis of Matrix Components by Arterial Smooth Muscle Cells invitro Author, Vol 191, no. 4226, pp. 475-477, 2016. https://doi.org/10.1126/science. 128820

10. I. J. Sarembock et al., Influence of Inflation Pressure and Balloon Size on the Development of Intimal Hyperplasia After Balloon Angioplasty A Study in the Atherosclerotic Rabbit, vol. 01, pp. 1029-1041, 2015.

11. K. T., C. J.W., H. C.C., R. T.J., and F. D.P., Differences in compensatory vessel enlargement, not intimal formation, account for restenosis after angioplasty in the hypercholesterolemic rabbit model, Circulation, vol. 89, no. 6, pp. 2809-2815, 1994.

12. R. E. Kuntz, R. D. Safian, J. P. Carrozza, R. F. Fishman, M. Mansour, and D. S. Baim, The Importance of Acute Luminal Diameter in Determining Restenosis After Coronary Atherectomy or Stenting, vol. 10, no. Figure $1,1992$.
13. M. Azaouzi, N. Lebaal, A. Makradi, and S. Belouettar, Optimization-based simulation of self-expanding nitinol stent. Lect. Notes Mech. Eng., vol. 1, pp. 423-450, 2013.

14. C. J. Mills et al., Pressure-flow relationships and vascular impedance in man, 1970.

https://doi.org/10.1093/cvr/4.4.405

15. J. A. Ormiston, M. W. I. Webster, P. N. Ruygrok, J. T. Stewart, H. D. White, and D. S. Scott, Stent Deformation Following Simulated Side-Branch Dilatation: A Comparison of Five Stent Designs, vol. 264, no. December 1998, pp. 258-264, 1999.

16. Z. Ding and M. H. Friedman, Dynamics of Human Coronary Arterial Motion and Its Potential Role in Coronary Atherogenesis, J. Biomech. Eng., vol. 122, no. 5, p. 488, 2002. https://doi.org/10.1115/1.1289989

17. Z. Ding, H. Zhu, and M. H. Friedman, Coronary Artery Dynamics In Vivo, Ann. Biomed. Eng., vol. 30, no. 4, pp. 419-429, 2002.

18. E. S. Weydahl and J. E. Moore, Dynamic curvature strongly affects wall shear rates in a coronary artery bifurcation model, J. Biomech., vol. 34, no. 9, pp. 1189-1196, 2001.

19. A. Buradi and A. Mahalingam, Impact of coronary tortuosity on the artery hemodynamics, Integr. Med. Res., 2019.

20. J. Vetter, L. Rainoni, A. J. Leu, A. Bollinger, and A. Division, Popliteal artery compression and force of active plantar flexion in young healthy volunteers, $\mathrm{pp}$. 281-287, 1985.

21. D. Sh, B. Pusich, and G. Richter, Sirolimus-Eluting Stents for the Treatment of Obstructive Superficial Femoral Artery Disease Morphologic and Angiographic Features of Coronary Plaque Rupture Detected by Intravascular Ultrasound Feasibility and Ef fi cacy of Balloon-Based Neuroprotection, pp. 62-63, 2003.

22. C. Dumoulin and B. Cochelin, Mechanical behaviour modelling of balloon-expandable stents, J. Biomech., vol. 33, no. 11, pp. 1461-1470, 2000.

23. K. Kröger, F. Santosa, and M. Goyen, Biomechanical Incompatibility of Popliteal Stent Placement, J. Endovasc. Ther., vol. 11, no. 6, pp. 686-694, 2004.

24. J. Solis, S. Allaqaband, and T. Bajwa, A case of popliteal stent fracture with pseudoaneurysm formation, Catheter. Cardiovasc. Interv., vol. 67, no. 2, pp. 319-322, 2006.

25. E. E. Mcgrath and D. Warriner, The Insertion of Self Expanding Metal Stents with Flexible Bronchoscopy under Sedation for Malignant Tracheobronchial Stenosis: A Single-Center Retrospective Analysis. vol. 48, no. 2, pp. 43-48, 2012.

26. C. P. Saad, S. Murthy, and G. Krizmanich, Self-Expandable Metallic Airway Stents and Flexible Bronchoscopy Chest, vol. 124, no. 5, pp. 1993-1999, 2003. 
https://doi.org/10.1378/chest.124.5.1993

27. G. Dimofte, R. Moldovanu, F. Crumpei, O. Grigoras, and E. Tarcoveanu, Incomplete Deployment of an Expandable Metallic Stent in a Patient with Esophageal Malignant Stenosis, pp. 3-6.

28. C. K. Phua, E. A. Reyes, J. Abisheganaden, A. Y. H. Lim, G. S. Keng, and A. Verma, Failure of expansion of covered self-expanding metal stent during tracheal stenting: Case report, Case Reports Intern. Med., vol. 3, no. 1, pp. 3-5, 2015.

29. R. S. Schwartz and D. R. Holmes, Pigs, Dogs, Baboons, and Man: Lessons for Stenting from Animal Studies Neointimal Hyperplasia in Porcine, vol. 7, no. 4, 1994.

30. J. Bedoya, C. A. Meyer, L. H. Timmins, M. R. Moreno, and J. E. Moore, Effects of Stent Design Parameters on Normal Artery Wall Mechanics, J. Biomech. Eng., vol. 128, no. 5, p. 757, 2006.

31. C. Lally, F. Dolan, and P. J. Prendergast, Cardiovascular stent design and vessel stresses: A finite element analysis, J. Biomech., vol. 38, no. 8, pp. 1574-1581, 2005.

32. P. J. Prendergast, Analysis of Prolapse in Cardiovascular Stents: A Constitutive Equation for Vascular Tissue and Finite-Element Modelling, J. Biomech. Eng., vol. 125, no. 5, p. 692, 2003. https://doi.org/10.1115/1.1613674

33. P. D. Ballyk, Intramural Stress Increases Exponentially with Stent Diameter: A Stress Threshold for Neointimal Hyperplasia, no. 4, pp. 1139-1145.

34. M.N. Roslan, A.E. Ismail, M.Y. Hashim, M.H. Zainulabidin, S.N.A. Khalid, Modelling analysis on mechanical damage of kenaf reinforced composite plates under oblique impact loadings. Applied Mechanics and Materials, 465-466, 1324-1328, 2014.

35. A.E. Ismail, A.K. Ariffin, S. Abdullah, M.J. Ghazali, R. Daud, Mode III stress intensity factors of surface crack in round bars. Advanced Materials Research, 214, 192-196, 2011.

36. A. Hamdan, F. Mustapha, K.A. Ahmad, A.S. Mohd Rafie, M.R. Ishak, A.E. Ismail, The Effect of Customized Woven and Stacked Layer Orientation on Tensile and Flexural Properties of Woven Kenaf Fibre Reinforced Epoxy Composites. International Journal of Polymer Science, 2016, 6514041, 2016.

37. A.E. Ismail, M.A. Hassan, Low velocity impact on woven kenaf fiber reinforced composites. Applied Mechanics and Materials, 629, 503-506, 2014.

38. A.E. Ismail, M.H. Zainulabidin, M.N. Roslan, A.L. Mohd Tobi, N.H. Muhd Nor, Effect of velocity on the impact resistance of woven jute fiber reinforced composites. Applied Mechanics and Materials, 465-466, 1277-1281, 2014.

39. A.E. Ismail, A.L. Mohd Tobi, Axial energy absorption of woven kenaf fiber reinforced composites. ARPN Journal of Engineering and Applied Sciences, 11(14), 8668-8672, 2016.
40. A.E. Ismail, Multiple crack interactions in Bi-Material plates under mode I tension loading. Applied Mechanics and Materials, 629, 57-61, 2014.

41. A.E. Ismail, A.K. Ariffin, S. Abdullah, M.J. Ghazali, Stress intensity factors for surface cracks in round bars under combined bending and torsion loadings. International Review of Mechanical Engineering, 4(7), 827-832, 2010. 